Revista de Ciencias Sociales - Número 64 (2014) - Páginas 13-45

Sobre Utopías, antitutopías y liberación. Aproximaciones y precisiones desde...

\title{
SOBRE UTOPÍAS, ANTIUTOPÍAS Y LIBERACIÓN. APROXIMACIONES Y PRECISIONES DESDE LATINOAMÉRICA
}

ABOUT UTOPIAS, ANTIUTOPIAS AND LIBERATION. APPROACHES AND PRECISIONS SINCE LATIN AMERICA

LORENA ZUCHEL LOVERA*

Departamento de Estudios Humanísticos Universidad Federico Santa María, Chile lzuchel@gmail.com

\section{Resumen}

En el presente artículo se intentarán identificar aquellas versiones sobre el concepto de utopía que hemos tenido presente en Latinoamérica, verificando que la utopía ha formado parte importante de la constitución de nuestra identidad, pero también ha sido mecanismo de encubrimiento y de opresión para la configuración de la misma. Se concluirá este trabajo exponiendo a la utopía como liberación, desde algunas propuestas de la filosofía latinoamericana.

\section{Palabras claves}

Utopía, Antiutopía, Identidad, Latinoamérica, Liberación.

\footnotetext{
* Doctora en Filosofía por la Universidad de Deusto. Artículo recibido el 12 de mayo de 2014 y aceptado el 24 de junio de 2014.
}

Revista de Ciencias Sociales - Número 64 (2014) - Universidad de Valparáíso - ISSN 0716-7725-Valparaíso, Chile 


\section{Abstract}

The following article is aimed at identifying the different meanings we have had in Latin America about the utopia concept; ensuring that utopia has played an important role in building our identity, while it has also been used as a means of masking and oppression for its own configuration. The work would conclude with an exposition of the utopia as liberation, from some proposals of Latin American philosophy.

\section{Keywords}

Utopia, Anti-Utopia, Identity, Latin America, Liberation

\section{Una introducción al concepto de utopía}

Si buscamos en el diccionario el significado de utopía, nos encontraremos con la idea de un plan, de un proyecto o de una doctrina irrealizable en el momento de su formulación ${ }^{1}$ o dicho de otra forma, proyecto que es a la vez deseable e inalcanzable. Pues bien, lo que hasta ahora ha generado el concepto, según se destaca de los más famosos "utopistas", son la idea de vacío y de falta de legitimidad real; así mismo, la utopía parece representar en los escritos utópicos una idea cerrada de historia, pues la perfección de sus propuestas no dejaría chance para ningún cambio, para ninguna nueva batalla, al quedar todo resuelto ${ }^{2}$. Esta idea negativa se puede contrarrestar con una formulación de utopía que está presente en el mismo ánimo inicial que la propone, y es el ánimo de superación, de mejorar una estado en crisis, y desde aquí, el intento político de transformación de la sociedad. Este deseo de reforma que anima positivamente las utopías, sea quizá el que alentó a los u topistas del renacimiento, que usaron por vez primera dicho término.

1. Cfr., Real Academia Española, Madrid, 2014. www.rae.es/Utopía. [Consultado en mayo de 2014].

2. Cfr., FERRATER MORA, José: Diccionario de Filosofía, Editorial Sudamericana, Buenos Aires, 1965. Pág. 862. Definición extraída por la Real Academia Española del libro Utopía de Tomás Moro.

Facultad de Derecho y Ciencias Sociales - Universidad de Valparaíso - Chile 
En las utopías renacentistas encontramos un incipiente fervor por el reciente hallazgo del continente americano. Dicho de otro modo: tras el "Descubrimiento" de América, se escribe la Utopía de Moro (en 1516), y se populariza el término. ¿Por qué América? En este nuevo lugar, bello y despoblado, para los ojos de sus conquistadores, se encuentra un lugar para desatar los sueños ocultos y oprimidos de nuevas opciones, como también los temores y disgustos de un continente viejo y desesperado. En América situó el europeo sus esperanzas, y las oportunidades de un anhelo renacentista. América aparece, para el europeo, en el momento que más lo necesitaba. Esto lo podemos notar en los propios escritos de Moro donde describe la fatídica realidad de una Europa, cuyos nobles son gente ociosa y haragana, que viven del trabajo opresivo de los demás sólo para enriquecerse ${ }^{3}$. Donde relata además la violencia con la que actúan los ejércitos, quienes son capaces de arrasar con pueblos enteros sólo para mantenerse activos ${ }^{4}$. En América, entonces, como en aquella isla Utopía, cuyo lugar no existe, o es demasiado lejano y antiguo para acceder a él ${ }^{5}$, se emplazó el anhelo de paz y de justicia, de trabajo justo y equitativo, y de una equidad tal, que uniformaba todos los ámbitos de la vida, con una simpleza extrema que se podía incluso confundir con la de la propia naturaleza. Es así como se crean islas maravillosas, que describían desde escuetas noticias enviadas por los conquistadores, fantasías insuperables, lejanas y aisladas de toda corrupción, como de un sistema de economía agrícola de trabajo de la tierra. De aquí que es posible encontrar también en estas utopías la imagen paradigmática de la República de Platón, que bien calzaba con las ilusiones del nuevo continente. De ella, por ejemplo, Tomaso Campanella sostiene la claridad y sencillez ${ }^{6}$ de este nuevo lugar de justicia ideal, que es recreada en su Ciudad del Sol.

3. MORHE, Thomas: Utopía, Ediciones Akal, Madrid, 1997, págs. 8 y ss.

4. Cfr., Ídem.

5. Cfr., HOPENHAYN, Martín: "Utopías del Renacimiento, Moro, Campanella y Bacon”, en Estudios Públicos, N³9, Santiago de Chile, 1990. Pág. 304.

6. "Son pocas, breves y claras y están escritas en una tabla de bronce" resalta Campanella de las leyes de esta Ciudad, evocando una visión moderna del

Revista de Ciencias Sociales - Número 64 (2014) - Universidad de Valparáíso - ISSN 0716-7725-Valparaíso, Chile 
La sencillez natural de la nueva tierra fue lo primero que maravilló al europeo, y ello fue lo que motivó al renacentista, que vio en el acto de conquista la posibilidad de empezar de nuevo, a escribir sus esperanzas. No obstante, todo lo que ocurrió en el nuevo lugar descubierto, los nuevos feudos levantados, la violencia indiscriminada hacia los nativos y la usurpación de sus tierras y riquezas, no fueron contados por estos pensadores, cuan ciegos y sordos, hablaron desde sus escritorios de una tierra de posibilidades, de una nueva clase de humanidad. La utopía renacentista cumplió su misión para Europa, pero fue la destrucción de una tierra otra; mas en el acto, fue también motivo de construcción de utopías, opuestas, para los que no cabían en el ideal europeo.

En este contexto, Rojas Mix presenta la utopía como un impulso que identifica nuestro continente; desde su descubrimiento y para toda la historia de Nuestra América:

"Aparece en cinco momentos: en el descubrimiento, poblando el viaje al oeste de tierras míticas; en la colonización, con las utopías cristiano-sociales que protegieron al indio; en la independencia, asociada a la declaración de los derechos del hombre y del ciudadano y a las ideas de tolerancia, igualdad y contrato social [...] la idea de una América unida formaría parte también de esta utopía; en el periodo de formación de los nuevos estados; en el pathos colonizador y en la idea continental que nace de la crítica al progreso; y, finalmente, en el pensamiento contemporáneo, en las preocupaciones puramente continentales, identitarias, en el americanismo de muchas corrientes literarias, ideológicas y revolucionarias, orientadas por un 'paradigma de futuro americano""'

pensamiento, que se manifiesta paradigmáticamente en René Descartes. En CAMPANELLA, Tomaso: La ciudad del sol, Fondo de Cultura Económica, México, 1980. Pág. 187.

7. ROJAS MIX, Miguel: Los cien nombres de América: eso que descubrió Colón, Editorial de la Universidad de Costa Rica, Costa Rica, 1997. Págs. 203-204.

Facultad de Derecho y Ciencias Sociales - Universidad de Valparaíso - Chile 
Estos momentos son también responsables de toda y cada una de las proyecciones que ponen uno y mil nombre a un territorio ya habitado, pero que nadie ve. En este sentido, el nombre Nuevo Mundo, Nuestra América, Latinoamérica, o Panamérica, entre otros tantos que nos recuerda Rojas Mix en aquella obra, son también representaciones utópicas de cien y más ideologías que pretenden resolver la historia sufrida de algún pueblo que quiere y necesita una utopía. Como diría Horacio Cerutti Guldberg: "la utopía aspira al cambio efectivo, real, eficiente, justamente, en la medida en que la situación presente le resulta intolerable" 8 .

Desde esta interrogante debemos partir reconociendo, entonces, unas primeras características de la utopía: la utopía como sinónimo de insatisfacción —como podemos ver claramente en los escritos de Moro-, pero también como modelo de transformación, como proyecto crítico de un deseo de cambio - como pasa con los anhelos de muchos pensadores latinoamericanos del siglo XIX, por ejemplo-.

Ahora bien, debemos distinguir entre las utopías de unos y las utopías de otros; pues todas, han sido pensadas desde lugares existenciales distintos, lo que hace que éstas tengan ánimos e intencionalidades disímiles. Desde aquí que aproximarnos a su formalidad nos pueda ayudar en la reflexión.

Para Arnhelm Neusüss, por ejemplo, en su libro recopilatorio Utopía, el concepto ha carecido de carácter analítico, pues se ha conformado simplemente en ser clasificatorio, y por ende se exterioriza como un pensamiento ingenuo. Así mismo, esta característica de clasificación propia de las utopías se encuentra — según Neusüsspresente en las distintas corrientes utópicas, de las que comenta es posible por lo menos distinguir tres:

"En primer lugar aquella que establece como criterio de lo utópico una serie de características formales que se dan en fenómenos literarios; en segundo lugar, aquella que señala como

8. CERUTTI GULDBERG, Horacio: De varia utópica (Ensayos de Utopía III), Publicaciones de la Universidad Central de Bogotá, Colombia, 1989. Pág. 162.

Revista de Ciencias Sociales - Número 64 (2014) - Universidad de Valparáíso - ISSN 0716-7725-Valparaíso, Chile 
utópica una determinada y antigua fase del pensamiento sociológico, caracterizada por métodos pre-científicos; y finalmente, a ciertas intenciones relacionadas con la organización de la convivencia social. No siempre se pueden distinguir estas variantes de forma rigurosa, también existen algunas proposiciones de desligar por completo la definición del concepto de utopía de cualquier vinculación con la esfera social, convirtiendo el momento de la anticipación de lo futuro en la característica esencial del concepto de utopía. No obstante, el carácter clasificador y descriptivo del concepto persiste en todas las variantes" .

No de acuerdo con estas aproximaciones encontramos a Cerutti Guldberg, pues para él, en ningún caso, las utopías, en cuanto son utopías, serán ingenuas, pues algo que tienen es "exceso de realismo" ${ }^{10}$. Para Cerutti lo que es fundamental en las utopías es que estas posean un "horizonte utópico", cosa distinta al "género utópico", del "ejercicio utópico" y el "razonamiento utópico", pues el primero es "una alternativa a la institucionalidad vigente" ${ }^{11}$.

Por otro lado, se han distinguido también tres formas de situar los escritos utópicos en autores más recientes, que parecen lograr consenso entre los historiadores, y aunque sin alejarse en demasía de las recién comentadas por Neusüss, rescata el valor antropológico de las distintas modalidades utópicas. Nos referimos a las trabajadas por Rogelio Blanco en su libro La ciudad ausente ${ }^{12}$. Estas son: La mentalidad utópica, que, así como lo describía Neusüss, da a conocer fenómenos sociales a través de formas literarias, y que son típicas del Renacimiento

9. NEUSÜSS, Arnhelm: Utopía, Barral Editores, Barcelona, 1971. Pág. 14.

10. SANTOS, José: Conflicto de Representaciones. América Latina como lugar para la filosofía, FCE, Santiago de Chile, 2010. Pág. 198.

11. Ibídem., pág. 196.

12. BLANCO, Rogelio: La ciudad ausente. Utopía y Utopismo en el pensamiento occidental, op. cit. Págs. 69-70.

Facultad de Derecho y Ciencias Sociales - Universidad de Valparaíso - Chile 
y de la Ilustración aunque igualmente cultivadas en nuestra época en autores como Huxley y Orwel; en segundo lugar, el pensamiento utópico, utilizadas en primer lugar por Platón y por los filósofos del socialismo; y por último, la intención utópica, que - expresa Blanco- como se advierte en las defensas de Roger y algunos miembros de la Escuela de Frankfurt (Horkheimer, Bloch y Jünger) más allá de la forma, destaca de ellos como utópica su intención ${ }^{13}$. También se puede situar aquí la tradición que ya se arrastra desde Bacon, pasando por los teóricos del Contrato social como Hobbes y Rousseau.

Ahora bien, el mismo Blanco reconoce que esta calificación u opción por agruparlos es claramente arbitraria, y que podemos encontrar en la utopía un género que va desde la intencionalidad social más antigua, como se refleja en la obra de Moro, hasta la intencionalidad narrativa e inquietante de Eumeswil o de Heliópolis de Ernest Jünger ${ }^{14}$. Así pues, lo que hay que considerar al pensar la utopía es que ésta se ha ubicado en diferentes épocas y lugares, como también se ha expresado en una variedad de géneros, mas todos ellos con una máxima a alcanzar: la felicidad; felicidad con distintos matices, pero incorporando, al fin, la idea de summum ontológico, y de recreación individual, que caracteriza los propósitos de cada cual. Propósitos, que para algunos tiene claros ribetes psicológicos, expresados en el binomio utopíaideología, que han caracterizado las aportaciones de Karl Mannheim. En ellas se descubre un esfuerzo por elaborar planteamientos lógicos que puedan criticar la realidad presente, a través de inspiración en el pasado, y trascenderlo, a través de una realidad futura ${ }^{15}$ — como exigía Cerutti Guldberg-.

En efecto, Mannheim, en su libro Ideología y utopía, reflexiona sobre la fundamentación ontológica de esos dos conceptos. Afirma la existencia de ciertas corrientes inspiradoras de la historia que distingue

13. Sobre esta idea recomiendo leer también a Cortina, Adela, Crítica y utopía: La escuela de Frankfurt, Cincel, Madrid, 1985. Págs. 120 y ss.

14. Cfr., BLANCO, Rogelio: La ciudad ausente, op. cit. Pág. 70.

15. Cfr., MANNHEIM, Karl: Ideología y utopía. Una introducción a la sociología del conocimiento, Fondo de Cultura Económica, México, 1987.

Revista de Ciencias Sociales - Número 64 (2014) - Universidad de Valparáíso - ISSN 0716-7725-Valparaíso, Chile 
como ideología y utopía, y que se manifiestan intelectivamente en cada marco social, o en la realidad histórica concreta. Según Mannheim, estos conceptos son diferentes y opuestos, y por ello, la forma de enfrentar las discrepancias entre esos dos polos es situándose al centro del conflicto y no a favor de uno de los extremos, como lo hizo Marx a favor del proletariado, por ejemplo. Esto, a pesar de su insistencia en la imposibilidad de cualquier teoría o clase humana de señalar una versión de la vida como libre de desideologizaciones, y de un cierto relativismo en sus teorías, que no daban por absoluta ninguna verdad, pues las distintas perspectivas de representación del mundo dependerían siempre de un determinado marco social:

"Ni un dios podría formular una proposición, sobre temas históricos, que fuera el equivalente de: 2 × $2=4$, pues lo inteligible en la historia se puede formular únicamente con relación a problemas y construcciones conceptuales que surgen a su vez en el devenir de la experiencia histórica" ${ }^{16}$.

Pero Mannheim, en aquel mismo libro insiste - como decíamos - en la búsqueda de la realidad por medio de los conceptos ideología y utopía. En el caso de la utopía, según Mannheim, si bien aún no se realiza, está destinada a realizarse, por ello pasa a ser un paradigma conductual como función racional y rectora de los actos humanos; como también una forma de contrarrestar y diferenciar lo que al fin resultan ser meras ideologías. Las ideologías, por otro lado, "son las ideas que trascienden la situación y que nunca lograron, de hecho, realizar su contenido virtual. Aunque a menudo se convierten en los motivos bien intencionados de la conducta del individuo, cuando se las aplica en la práctica, se suele deformar su sentido"17. Además, éstas se terminan adaptando a la realidad, confirmando su posibilidad, pues poseen una manera poco revolucionaria de actuación ${ }^{18}$. Pues bien,

16. Cfr., Ibídem. Pág. 70.

17. Ibídem. Pág.171.

18. Cfr., Ídem.

Facultad de Derecho y Ciencias Sociales - Universidad de Valparaíso - Chile 
la eficacia de la acción será al fin lo que determine lo que es utópico o no, es decir, un resultado histórico en el que se devela a posteriori si tal proyecto era o no verdadero.

Lo interesante del pensamiento de Mannheim para este escrito recae, más allá de sus aportaciones en la elaboración de su sociología del conocimiento, en la posibilidad utópica de ir superando la historia temporal, a través de una crítica y desvelamiento de las ideologías que la subyacen, y consolidando el concepto de utopía que al fin da oportunidades de superación y esperanza a la realidad histórica, impulsándola hacia adelante, hacia lo que debe llegar a ser.

Por otro lado, Ernst Bloch acepta el carácter intencional de la utopía, calificándolo como anticipadora y esperanzadora, como reveladora y creadora ${ }^{19}$. Sin embargo no está de acuerdo con Mannheim y su especial relativismo, por alejarse de lo que según él es central del concepto de utopía. Pues, para Bloch, más allá de su primera concepción de "filosofía por venir" — que luego fue tratado como realización humana en el futuro-, posee una cierta función que él cree es demoledora, sobre todo por el poder de transformación que ella conlleva en su horizonte utópico concreto. Nos referimos a la esperanza.

"El contenido del acto de la esperanza es, en tanto que clarificado conscientemente, que explicitado escientemente, la función utópica positiva: el contenido histórico de la esperanza, representado primeramente en imágenes, indagado enciclopédicamente en juicios reales, es la cultura humana referida a su horizonte utópico concreto" ${ }^{20}$.

Este poder de transformación, entonces, se aleja ya de la simple denuncia de los primeros utopistas (como las denuncias que enfatizaba Tomás Moro), pues Bloch asume la idea marxista de materialidad y derrocamiento de las relaciones que degradan al ser humano. Esto lo hace de una forma seria y responsable, asumiendo el contenido de la

\footnotetext{
19. Cfr., BLOCH, Ernst: El principio esperanza, Aguilar, Madrid, 1977.

20. Ibídem. Págs. 135-136.
}

Revista de Ciencias Sociales - Número 64 (2014) - Universidad de Valparáíso - ISSN 0716-7725-Valparaíso, Chile 
utopía como lo que efectivamente se puede realizar. De esta manera, se genera un optimismo que promueve a las personas a creer en las transformaciones, y a trabajar en el presente por conseguirlas.

La esperanza, para este autor, entonces, es el elemento clave de su filosofía, pues a través de ella se puede realizar, como hemos comentado, la función utópica. La esperanza es el motor que impulsa, en medio de un sin número de posibilidades, la praxis de las alternativas necesarias para hacer real lo que en presente es utopía; de ahí las acciones liberadoras que podrán ir haciendo al ser humano realmente autor de la historia.

Así pues, el concepto de praxis es sumamente importante al momento de definir lo más propio de la realidad, y la futurización a través de una utopía. Pues la praxis es aquella posibilidad anticipadora del ser que va en proceso configurando una realidad plena que está por venir.

Ahora bien, más allá de las formas, de los contenidos, la función utópica que se va desarrollando, Bloch nos invita a reevaluar el pensamiento marxista, como lucha en contra de las sociedades de clases, y a darle aquel anclaje utópico que recae en una ontología de la esperanza, en contra de toda ideología deformadora de la realidad. Podemos decir, incluso, que la utopía blochiana nace en Marx, aunque, como nos afirma Ramos Centeno: "no precisamente porque Marx haga pintura alguna del Estado futuro, o porque nos describa algún futuro paraíso en la tierra, como hacían las utopías abstractas, sino porque él insistió - contra lo que hacían aquellas — en la crítica del presente, en el descubrimiento de la dialéctica material de la historia, de las tendencias y latencias del presente que permiten buscar el camino hacia el futuro humano, en el que el 'imperativo categórico' puede ser realidad" ${ }^{21}$.

En efecto, aunque se opone la utopía a la ideología, en cuanto trata de transformarla, no son, como pensaba Mannheim, estrictamente contrapuestas, ya que la utopía es parte de la realidad, con todo lo que ella es, aunque tensada hacia su liberación, y hacia su verdad.

21. RAMOS CENTENO, Vicente: Bloch, (1885-1977), Ediciones del Orto, Madrid, 1999. Pág. 37.

Facultad de Derecho y Ciencias Sociales - Universidad de Valparaíso - Chile 
He aquí una segunda característica que podemos encontrar en los proyectos utópicos: el deseo de develar la verdad; o dicho de otro modo: la utopía como utopía de la liberación.

Antes de preguntarnos qué son y qué persiguen las utopías de la liberación, es preciso preguntarnos si es posible cualquier tipo de utopías. Como veremos, hay posturas que indican que sólo son palabras, promesas gatopardísticas que confunden las verdaderas necesidades del presente, y sus posibilidades de solución. Estas hipótesis, además, han sido fuertemente incorporadas a los fundamentos de las estructuras organizativas de variados países latinoamericano, entre ellos, Chile; país que ha sido nicho de estudio por su excelente inserción del sistema neoliberal; sistema que en sus bases rechaza explícitamente el concepto de utopía.

\section{2. ¿Es posible creer en las utopías? Una introducción al concepto de anti-utopía}

La pregunta que enmarca este apartado no es de tan fácil consenso como el que hasta ahora hemos introducido; pues expresar una actual disposición al término, es, al parecer, cuestión cada vez más complicada. Esto es así por la realidad que caracteriza nuestros días, que a veces nos desborda y nos impide comprometernos en un accionar distinto al que hemos ido acostumbrando nuestros actos, pero también, porque la intencionalidad que se ha implantado desde hace ya un tiempo, descansa en un claro desprestigio por parte de pensamientos anti-utópicos. ¿Qué entenderemos por anti-utopías? El ideario ya no de ciudades maravillosas, sino de relatos de un caos, que de igual forma pretende ser lugar de denuncia de su posibilidad de constitución. Ahora bien, habrá que preguntarse más adelante si aquella intención que los caracteriza no los vuelve, de otro modo, impulsores de una nueva utopía anti-utópica. Con todo, algunas de las anti-utopías escritas en Latinoamérica no han sido denunciantes de un estado social establecido, sino sustentadoras del mismo, lo que ha provocado un desgaste del concepto utópico que antaño vivificó la emancipación de nuestros pueblos.

Revista de Ciencias Sociales - Número 64 (2014) - Universidad de Valparáíso - ISSN 0716-7725-Valparaíso, Chile 
Para introducirnos en esta problematización podemos referirnos a un escrito de Jürgen Habermas, de 1984, "El fin de la utopía”, en el que se muestra la dificultad de enfrentar hoy en día este tipo de pensamientos; todo esto, caracterizado por un cierto desprestigio del término, que se podría comprender desde dos momentos distintos de la realidad, que requerirían conceptos diferentes de legitimaciones del pensamiento.

El artículo expresa claramente que el espíritu de la época, que antaño recibió impulsos de las fuentes de la historia y de la utopía, y de manera conjunta y nutricia, hoy sólo lo hace desde la historia, tras el abandono del pensamiento utópico (tras la muerte de las utopías). Esto es para él claramente observable desde el desolador horizonte que se refleja en nuestros días:

"En el umbral del siglo XXI se dibuja el panorama aterrador de unos riesgos que, a nivel mundial, afectan a los propios intereses generales de la vida: la carrera de armamentos, la difusión incontrolada de las armas nucleares, el empobrecimiento de los países en vías de desarrollo, el desempleo y los crecientes desequilibrios sociales en los países desarrollados, problemas ecológicos, tecnologías que operan casi al borde de la catástrofe, son las rúbricas que a través de los medios de comunicación han penetrado en la conciencia pública. Las respuestas de los intelectuales, no menos que las de los políticos, reflejan desconcierto"22.

Con todo, para Habermas no está claro que sea la muerte de la utopía, como de "toda" utopía, la que ha abandonado la vertiente histórica que caracterizó la modernidad, sino precisamente la utopía de aquella modernidad, que refleja otros tiempos, con otros paradigmas. En efecto, lo que realmente han culminado son aquellas utopías que dieron luz a la lucha entre burgueses y proletariado, entre patrón y

22. HABERMAS, Jürgen: "El fin de una utopía”, El País, 9 de diciembre de 1984. Págs. 14-15. Discurso pronunciado en Madrid, en el Congreso de los Diputados, el 26 de noviembre de 1984.

\footnotetext{
Facultad de Derecho y Ciencias Sociales - Universidad de Valparaíso - Chile
} 
obrero, entre capitalistas y marxistas y, en general, un pasado definido en torno a la sociedad del trabajo; pero, en el acto, aunque a algunos pudiera servir el discurso sobre la muerte de estos ideales, y sobre todo si consideramos la situación actual esbozada, queda en Habermas la esperanza de la simbiosis histórico-utópica a través de una cierta conciencia de realidad, en la que se reconoce, a través de otros medios, la crítica social actual, convirtiendo los problemas en tema presente, y de cierta forma abogando a una nueva concepción de utopía:

"Lo que para la utopía de la sociedad del trabajo era presupuesto o condición marginal, hoy se convierte en tema. Y así, los acentos utópicos se desplazan del concepto de trabajo al concepto de comunicación. Y hablo nada más que de acentos, porque con este cambio de paradigma de la sociedad del trabajo a la sociedad de la comunicación cambia también el tipo de conexión con la tradición utópica. Ciertamente que con el abandono de los contenidos utópicos de la sociedad del trabajo no se cierra la dimensión utópica de la conciencia histórica y de la discusión política. Cuando los oasis utópicos se secan, se difunde un desierto de trivialidad y de desconcierto. Insisto en mi tesis de que el autocercioramiento de la modernidad se ve aguijoneado, lo mismo ahora que antes, por una conciencia de actualidad en la que se funden el pensamiento utópico y el histórico. Pero con los contenidos utópicos de la sociedad del trabajo desaparecen ilusiones que hechizaron la conciencia que tuvo de sí la modernidad" ${ }^{23}$.

Este modo de ver la realidad y salvaguardar el derecho de la utopía, no sólo reconoce su pervivencia, sino que la faculta de un cierto empoderamiento y necesidad, pero aludiendo a otros ejes de operatividad, tal como lo son el trabajo (desde una nueva visión de trabajo, aunque no por ello menos ingenua y criticable), y la solidaridad; pero que también deja espacio hacia una apertura actual de comunicabilidad entre los distintos mundos de vida (como introdujeron

23. Ídem.

Revista de Ciencias Sociales - Número 64 (2014) - Universidad de Valparáíso - ISSN 0716-7725-Valparáiso, Chile 
los Filósofos del Discurso y el "último" Dussel), y que ha tomado, en las últimas décadas, una versión de "acogida" que invita a una mejor relación entre las distintas culturas, como lo muestra la filosofía intercultural, y las propuestas de Raúl Fornet Betancourt ${ }^{24}$.

\subsection{Anti-utopías estancadas}

Entenderemos como Anti-utopías estancadas las anti-utopías que quieren prevenir las fuerzas que pudieran cambiar el estado social establecido.

Estas se darían en un tiempo en que la esperanza de un mañana no conlleva nada más que a mentiras y que, incluso, éste -nuestro tiempo- se caracteriza precisamente por ser un tiempo de “credulidades", en el que se acepta y descansa fácilmente en cualquier idea que contenga un poco de misterio ${ }^{25}$. Nos referimos a Peter Berger y a su obra Una gloria lejana, entre otras, que muestran que todo sueño o proyecto utópico es una ilusión que llevaría al caos o a la decadencia, aunque esto sea deseo de nueva vida, pues estas razones tan sólo dan fe de que la muerte se viste con aspecto de vida, como sueño de felicidad ${ }^{26}$.

Ante esto, Franz Hinkelammert en su libro Crítica de la razón utópica, delata que ese tipo de ideas pertenecen a "aquellos que sustentan el orden social, los que nunca son todos. Si fueran todos, el orden no sería precario. No obstante, aquellos que sustentan el orden, sostienen que cualquier reacción en contra del orden se debe al egoísmo y a la estupidez"27. Rechaza las ideas de Peter Berger de su sociología del conocimiento y lo increpa a responder "por qué el hombre sigue a

24. Cfr., FORNET-BETANCOURT, Raúl: Tareas y Propuestas de la filosofía Intercultural, de Concordia, serie Monografías, tomo 49, Aachen, 2009.

25. Cfr., BERGER, Peter: Una gloria lejana, Herder, Barcelona, 1994.

26. Cfr., BERGER, Peter: El Dosel sagrado: Elementos para una sociología de la religión, op. cit. Págs. 59-62.

27. HINKELAMMERT, Franz: Crítica a la razón utópica, Editorial DEI, San José, Costa Rica, 1990. Págs. 34-37.

Facultad de Derecho y Ciencias Sociales - Universidad de Valparaíso - Chile 
los proyectos egoístas y estúpidos. Si el egoísmo lleva al caos y la muerte, hay que saber por qué alguien sigue a un egoísmo que destruye una realidad, sin la cual ni éste, su egoísmo, sería posible. Y si lo hace por estupidez, hay que saber por qué no cambia de opinión como resultado de sus malas experiencias" ${ }^{28}$.

Lo que sucede, cree Hinkelammert, es que se propone, a modo de imposición, cierta legitimidad y naturalización del mundo construido socialmente, mediante su facticidad objetiva; de ello las personas no se preguntan si requieren otra objetividad al margen de su propia presencia ya instituida ${ }^{29}$. Esto da por hecho que la realidad que ve y vive Berger es una buena realidad; pues de otro modo no se aceptaría de primeras, o de segundas, que no pudieran caber incertidumbres, ni espacio para otro tipo de credulidades; o dicho en palabras de Hinkelammert, corresponde a un sueño conservador de la convivencia pacífica entre amos y esclavos; pues el esclavo se ha resignado a la muerte, ante la nula posibilidad que le da el amo a vivir ${ }^{30}$.

No obstante, Hinkelammert es claro en señalar que hay unas básicas contradicciones en las teorías de Berger, como las que versan sobre la plausibilidad perfecta en contradicción con su definición y concepto de realidad: "si la plausibilidad perfecta no puede ser imaginada coherentemente sino como sociedad sin clases, y si la sociedad sin clases es una sociedad sin un sistema institucionalizado fijado, entonces el concepto de realidad de Berger se desvanece completamente" ${ }^{31}$.

Es así como Hinkelammert se abalanza en contra de del orden actual establecido, por ser anti-utopías de la sociedad, mostrando el caos de una utopía socialista, y legitimando, en el acto, un pensamiento conservador del status quo. Pero esta forma de conservadurismo, presenta una constante crítica hacia los demás tipos de pensamiento y de sociedad;

\footnotetext{
28. Ídem.

29. Cfr. Ibídem. Pág. 65.

30. Ibídem. Pág. 40.

31. Ibídem. Págs. 51-52.
}

Revista de Ciencias Sociales - Número 64 (2014) - Universidad de Valparáíso - ISSN 0716-7725-Valparaíso, Chile 
crítica que en todo caso se sostiene desde la necesidad de resguardar específicamente la sociedad burguesa. Para ello, se lanza en contra de las sociedades socialistas existentes, mostrándolas como ilegítimas (esto lo distingue del pensamiento liberal original que, con las mismas intenciones de legitimación de la burguesía, se abalanzó en contra de las sociedades pre-capitalistas) ${ }^{32}$, y fundamentado también en una visión precaria de la realidad, pero acotando la realidad a algunos elementos institucionales.

Estos elementos se restringen a un eje acotado por el mercado, quien, en la sociedad precaria en la que viviríamos, se ve nuevamente la amenaza del egoísmo y la estupidez. Por consiguiente proponen contrarrestar polarizadamente las circunstancias caóticas a las que conduce el socialismo, a partir de modelos progresivamente perfectos que se enuncian finalmente como una competencia perfecta. Sin embargo, ni el caos ni la competencia perfecta son conceptos factibles o empíricos, sino que pertenecen al ámbito de las abstracciones interpretativas, con las cuales se pretende otorgar cierta trascendentalidad a la interpretación limitada de la realidad empírica; y limitadamente, porque, como indica Hinkelammert, de ninguna manera estos son conceptos arbitrarios ${ }^{33}$.

Si es el mercado el que marca la institucionalidad de las sociedades, fuerza a estos pensadores a establecer mecanismos de equilibrio perfecto en los cuales la producción se descifraría en ecuaciones matemáticas que explicarían, por ejemplo, los precios de cada producto (caeteris paribus); pero la realidad, que no es constante, y que muestra situaciones cambiantes, provoca de partida una falla de adaptación que es imposible de calcular, por lo que esta teoría se haría inalcanzable.

Ahora bien, dada la imposibilidad de fundamentar adecuadamente un equilibrio idealizado, no se quedarán tampoco en el fomento de una cierta teoría ideal, sino que harán el intento de aproximarse $^{34}$ al equilibrio empíricamente. Para ello requerirán dos

32. Cfr., ibídem. Pág. 55.

33. Cfr., ibídem. Pág. 56.

34. La aproximación en Hayek se vuelve fundamental, pues para él es imposible el conocimiento empírico absoluto. De más está decir que lo que no es empírico

Facultad de Derecho y Ciencias Sociales - Universidad de Valparaíso - Chile 
condiciones que adelantan a cada propuesta de sociedad, y que son: la libertad de contrato en todos los mercados y actividades (a lo que hoy se le da el nombre flexibilidad laboral), y la propiedad privada ${ }^{35}$.

Estas vueltas y círculos viciosos que tratan de justificar cada concepto teórico, y que se van dando como acción dinámica temporal, tratan, como en el caso de los conservadores, de enfrentarse a las revoluciones utópicas que llevan al caos, y a la amenaza del orden social estable, en superación de la sociedad burguesa. Dicho enfrentamiento, lo realiza Friedrich Hayek en forma de crítica al socialismo, crítica que se puede resumir en tres etapas, que Hinkelammert esquematiza de la siguiente forma ${ }^{36}$ :

1) La utopía socialista es el proyecto de una sociedad sin relaciones mercantiles. Esta tendría que determinar los productos que se producen, los factores que se emplean y el abastecimiento de las personas sin recurrir al mercado. Eso es solamente posible, si por lo menos un individuo tiene conocimiento perfecto del conjunto de todos los acontecimientos.

2) Es imposible que alguna persona o institución pueda tener un conocimiento perfecto que haga posible una planificación tal que pueda sustituir el mercado en su función de asignación de los recursos.

no es posible tampoco de alcanzar; y de hecho, si así se tratase de hacer, se convertiría en su contrario. Querer alcanzar a Dios mismo, por ejemplo (en el caso de que él fuera Verdad), es para el ser humano querer ser Lucifer; es decir, lo convierte en lo inverso, "en algo malo y dañino para todos". Cfr., HAYEK, Friedrich: "La Pretensión del Conocimiento”, en ¿́nflación o pleno empleo?, Unión Editorial, Madrid, 1976, y HAYEK, Friedrich: "Entrevista en el Mercurio", en diario El Mercurio, 12 de Abril de 1981, Santiago de Chile. Págs. D8-D9.

35. Cfr., HAYEK, Friedrich: "La Pretensión del Conocimiento", en ÍInflación o pleno empleo?, Unión Editorial, Madrid, 1976.

36. HINKELAMMERT, Franz: Crítica a la razón utópica, op. cit. Pág. 63. 
3) El socialismo hace el intento de efectuar una planificación central capaz de sustituir el mercado como ámbito de asignación de los recursos; el socialismo es irracional, y produce caos, destrucción y tiranía.

Este intento de sustituir al mercado, para Hayek, es sinónimo de utopía: representa lo imposible, pero que el humano cree posible. Por lo tanto se deduce que la utopía es aquel camino que conduce a una inhumanidad total, pues es lo que impide al ser humano llegar a ser lo que puede en verdad ser. Ahora bien, como la utopía no es factible, el error está en el utopista, quien piensa y propone una perfección irrealizable, y por ello todo comportamiento que se razone desde esa imposibilidad será dañino, causará caos y destrucción ${ }^{37}$.

Hoy en día el pensamiento neoliberal se ha masificado por medio del sistema globalizado de mercado. Con ello, nos comenta Hinkelammert, se han transformado incluso los sistemas de valores de las sociedades, en cuanto el criterio formal de la eficiencia de mercado ha pasado a ser criterio supremo, sin ser debidamente criterio, pero transformándolos y dominándolos todos ellos, incluso los derechos humanos. Esto no deja espacio para que haya nuevas alternativas, porque cualquiera que se escape a esta mirada estaría obstaculizando el desarrollo de las fuerzas productivas ${ }^{38}$.

Para Hinkelammert, esta fuerza del desarrollo productivo ha llegado a disolver inclusive las polaridades de Primer Mundo-Tercer Mundo que se contrastaban como fuerzas antagónicas de un triunfo económico y social. Estas polaridades hoy han menguado sus diferencias de tal forma que se puede hablar incluso de "una nueva polarización del mundo", en que el polo dominante (en el que se encontraban los países "desarrollados") ha perdido su carácter de modelo, de aquel modelo que antaño poseía un rostro humano, y que, cuan pastor, podía

37. Cfr., HAYEK, Friedrich: "La Pretensión del Conocimiento", op. cit. Págs. 23-32.

38. HINKELAMMERT, Franz: El nihilismo al desnudo. Los tiempos de la globalización, LOM ediciones, Santiago de Chile, 2001. Pág. 32.

Facultad de Derecho y Ciencias Sociales - Universidad de Valparaíso - Chile 
ser capaz de conducir a las ovejas a una tierra buena, hacia un lugar bueno. En efecto, no es que se haya acabado la supremacía, o el eurocentrismo, sino que, como opina este autor, después de la caída del muro los países centrales ya no se preocupan de mostrar rostro humano, porque "ya no lo necesitan, y se ahorran los costos que la producción de esta apariencia demanda. Se han destruido muros, para construir nuevos muros. Hoy, el Primer Mundo se ve más bien como un gran archipiélago que aparece por todos los lados, pero que surge en el mar circundante de espacios que ya no se puede integrar ni económica ni socialmente. Pese a que este archipiélago todavía está ubicado sobre todo en el Norte, la relación no se puede entender más como una relación Norte-Sur. Sí se la puede marcar en el sentido de una exclusión" 39 .

No obstante, sí se pueden reconocer en el mundo centros dominantes, como ciertos enclaves que dirigen con su poder la direccionalidad de esta corriente globalizadora (como un Espíritu absoluto); y para ello, ven necesario entonces reforzar las ideas de flexibilidad laboral, propiedad privada (aquellas condiciones que señalábamos anteriormente de los escritos de Hayek), como también los que más recientemente se han vuelto fundamentales para las economías neoliberales: la libre circularidad de las mercancías, y la intervención del Estado como apoyo de las políticas económicas de un nuevo orden. Justamente, la intervención del Estado toma un nuevo rol: pasa de ser un garante de las necesidades humanas a ser un garante de la sociedad del capital; de ser el Estado para el ser humano, a ser Estado para la globalización del mercado, siendo facilitador de "los flujos de mercancía y capitales, y fomentándolos por medio de subvenciones inmensas que superan en tamaño cualquier cantidad de subvenciones que el Estado social jamás efectuara" ${ }^{40}$.

Las alternativas, entonces, parecen estar condenadas al fracaso, simplemente porque todos los ejes de las naciones están centrados a estos mismos objetivos. En ellos, como decíamos, incluso el pobre ha

\footnotetext{
39. Ibídem. Pág. 12.

40. Ibídem. Pág. 13.
}

Revista de Ciencias Sociales - Número 64 (2014) - Universidad de Valparáíso - ISSN 0716-7725-Valparaíso, Chile 
pasado a ser una pieza más del engranaje; pero también porque las alternativas han sido presentadas como utópicas, y la utopía, como sinónimo de caos, o más aún, en términos popperianos, como el infierno mismo: "La hibris que nos mueve intentar realizar el cielo en la tierra, nos seduce a transformar la tierra en un infierno, como solamente lo pueden realizar unos hombres con otros" ${ }^{41}$. Pero esta visión del austriaco fue precedida por Hegel con las siguientes palabras:

"Desarrolladas hasta convertirse en fuerza, esas abstracciones han producido, realmente, por un lado, el primero y — desde que tenemos conocimiento en el género humano- prodigioso espectáculo de iniciar completamente de nuevo y por el pensamiento la constitución de un Estado real, con la ruina de todo lo que existe y tiene lugar, y de querer darle como fundamento la pretendida racionalidad; por otro lado, puesto que sólo son abstracciones privadas de ideas, han hecho de esta tentativa un acontecimiento demasiado terrible y cruel" ${ }^{2}$.

Terrible y cruel son los adjetivos que califican la imposibilidad de realización de algo; como lo fue para éste la propia Revolución Francesa, y que para Hayek y Popper, simbolizó luego particularmente la Revolución socialista. Esto, para el austriaco Karl Popper, representaba una forma de sostener su tesis máxima sobre la absoluta imposibilidad empírica que tiene entonces todo ser humano como toda institución humana de ir más allá de las cosas. Sobre esto Hinkelammert nos comenta:

"Popper no expresa este principio de imposibilidad en términos hipotéticos o de un 'todavía no', sino en términos categoriales. Sus juicios al respecto tienen más bien el carácter de juicios apodícticos que sostienen un 'nunca jamás', es decir, una

41. POPPER, Karl: La miseria del historicismo, Editorial Alianza, 1973. Pág. 18.

42. HEGEL, Friedrich: Filosofía del derecho, Editorial Claridad, Buenos Aires, 1968. Págs. 213-214.

Facultad de Derecho y Ciencias Sociales - Universidad de Valparaíso - Chile 
imposibilidad fatal e insuperable para la acción humana [...] se trata de una imposibilidad lógica'”43.

En su escrito Utopía y violencia, de 1947, Popper insiste en ello, y señala enfáticamente que la utopía se origina por poseer un modo errado de racionamiento. Argumenta:

"Una acción, podría argüirse, es racional si hace el mejor uso de los medios disponibles para lograr un determinado fin. Puede incurrir, sin duda, que sea imposible determinar racionalmente ese fin. Sea como fuere, sólo podemos juzgar racionalmente una acción y descifrarla como racional o adecuada con respecto a un fin dado. Sólo si tenemos un fin, y sólo con respecto a tal fin, podemos decir que actuamos racionalmente" ${ }^{44}$.

Por lo tanto, en el caso de las políticas de Estado, por ejemplo, son para Popper razonables las argumentaciones que primero aclaren el tipo de Estado que se considere el mejor, para luego conducir lentamente los medios hacia él, "en cierta medida" — por cierto-, pues sólo en cierta medida - insiste- podremos influir y conducir hacia ese fin. Esto porque los fines jamás podrán ser explicados o argumentados científicamente; de ahí que aunque algunas proposiciones teleológicas puedan pretender ser argumentadas racionalmente, sólo cabe en ellas despejar ideas y ser claras para construir propuestas que lleguen a los que comparten también aquellas cuestiones. En consecuencia, para Popper la utopía es criticable porque ella, así como se enuncia y compromete, es perniciosa, y puede conducir —agrega — a la violencia. Esto lo explica del siguiente modo:

"Puesto que no podemos determinar los fines últimos de las acciones políticas científicamente o por métodos puramente racionales, no siempre es posible dirimir por el método de la argumentación las diferencias de opinión concernientes a cuál

43. HINKELAMMERT, Franz: Crítica a la razón utópica, op. cit. Pág. 160.

44. POPPER, Karl: “Utopía y violencia”, en NEUSÜSS, Arnhelm: Utopía, Barral Editores, Barcelona, 1971. Pág. 133.

Revista de Ciencias Sociales - Número 64 (2014) - Universidad de Valparáíso - ISSN 0716-7725-Valparáiso, Chile 
debe ser el Estado ideal. Tendrán, al menos parcialmente, el carácter de diferencias religiosas. Y no puede haber tolerancia alguna entre esas diferentes religiones utópicas. Los objetivos utópicos están destinados a ser la base de la acción política racional y la discusión, y tal acción sólo parece posible si se ha elegido definitivamente el objetivo. Así, el utopista debe conquistar o aplastar a sus utopistas rivales, que no comparten sus propios objetivos utópicos y no profesan su propia religión utopista" ${ }^{45}$.

Popper agrega que la violencia que conlleva este fenómeno se encargará de que el utopista aniquile a todos sus rivales y, de tan dura manera, que además garantice borrarlos de la memoria.

Tras esta crítica, Popper en el mismo artículo aconseja abandonar todo ideal que deba ser conseguido holísticamente, y todo fin que se deba imponer como asunto de Estado; como también olvidar los asuntos de "mundos maravillosos", y al contrario, fijar la vista en el trabajo cotidiano, que construye bondad y aconseja pacientemente a los que hacen el mal ha abandonar sus prácticas. Y concluye: "el logro de la felicidad debe ser dejado a nuestros esfuerzos privados" ${ }^{\$ 6}$, esfuerzos de una especie de dialéctica de la cotidianidad, que se intente hacer cargo del mal que nos rodea (como la miseria, la desocupación, guerras, enfermedades, etc.), y tratando de convertirlos en bienes de la forma más imparcial que se pueda. Ésta es para Popper la única manera de racionar correctamente sobre los asuntos políticos; no como los utopistas, que según él parten sus planeamientos con respecto a un fin histórico y no transitorio, sacrificando pequeños desenlaces por otro más lejano y superior:

"El atractivo del utopismo surge de no comprender que no podemos establecer el paraíso en la tierra. Lo que podemos hacer en cambio, creo yo, es hacer la vida un poco menos terrible y un

\footnotetext{
45. Ibídem. Pág. 135.

46. Ibídem. Pág. 137.
}

Facultad de Derecho y Ciencias Sociales - Universidad de Valparaíso - Chile 
poco menos injusta en cada generación. Por este camino es mucho lo que puede lograrse. Ya es mucho lo que se ha logrado en los últimos cien años. Nuestra propia generación puede lograr aún más. Hay muchos problemas acuciantes que podríamos resolver, al menos parcialmente [...] Podríamos lograr todo eso si abandonáramos los sueños de ideales distantes y dejáramos de luchar por nuestros esquemas utópicos de un nuevo mundo y un nuevo hombre" ${ }^{47}$.

Popper insiste en ello en La sociedad abierta y sus enemigos, donde argumenta que los grandes errores de los utopistas son las elaboraciones a gran escala, desarrollar una alternativa de sociedad en su totalidad donde se permite el tanteo, y el ensayo y error, con los que las personas, caminando hacia una sociedad abierta, se pueden confundir en libertad ${ }^{48}$.

En este sentido, podemos ver que Karl Popper se refiere a ciertas metas concretas a las que podríamos tender, como las que plantean rechazo hacia las situaciones de pobreza o de opresión, en general, y esto lo sugiere descartando toda planificación holística de la sociedad. Ahora bien, la separación y crítica entre utopía y metas concretas, aparece en Popper enfáticamente como rechazo hacia el socialismo, pero ello no se percibe como una crítica hacia la propia ideología burguesa. Es más, nos recuerda Hinkelammert que cuando éste reflexiona sobre las metas de la teoría burguesa lo hace desde unas metodologías de planificación económica que distan del cientificismo y que al fin caen en diseños de idealismos holísticos que también son compartidos por pensamientos de utopías socialistas (las que él critica), como de toda ciencia social ${ }^{49}$. Por otra parte esta disociación entre utopía y metas

47. Ibídem. Pág. 138.

48. POPPER, Karl: La sociedad abierta y sus enemigos, Paidós, Buenos Aires, 1967. Págs. 150-170.

49. Ver el caso del "método cero", en POPPER, Karl: La miseria del historicismo, Editorial Alianza, 1973. Pág. 156.

Revista de Ciencias Sociales - Número 64 (2014) - Universidad de Valparáíso - ISSN 0716-7725-Valparaíso, Chile 
posibles tampoco aceptan la institucionalización como medio de transformación, y sólo se refiere a ellas como formas de descripción de usos de ciertas instituciones, y no se arriesga incluso de ninguna forma a dar una definición concreta ${ }^{50}$.

Las críticas a Popper, sobre todo desde los filósofos latinoamericanos o de la liberación, han sido muchas, y el mismo Franz Hinkelammert en sus Críticas a la razón muestra distintas maneras por las cuales se puede encontrar a éste, o a Hayek - entre otros, como sustentadores de una civilización en la que sólo quepa el desarrollo económico de los mismos Estados de siempre. Y es que la creación de posibilidades mediáticas para mantener el orden actual pasivamente estable, sin transformar el fondo de las instituciones pasa por un desprestigio de todos los medios humanos socialmente establecidos, que permiten la redacción de una historia desde un ahora presente concreto como "todavía no, pero ya posible"; y más aún, descartan de paso toda forma de crítica "holística", que trata de mostrar, por contrasentido, todo lo que no existe en la historia, y que se resume en males y en penas para la mayoría de los habitantes del planeta.

Tratan de descartar la crítica holística que abarca el mercado y la economía, pero también el Estado y tantas otras instituciones y sistemas de realidad que permitiría acercarnos a una realidad más abierta y justa, a través de mecanismos de protección social. Formulan argumentos anuladores de discursos revolucionarios, o esperanzadores o utópicos (como quiera que se le llame), adjetivándolos como triviales e irrelevantes, o en algún momento, peligrosos; pues de ellos, claramente, "no se puede hablar" ${ }^{51}$, dejando sólo espacio - como argumentaba un reconocido filósofo danés- para el silencio místico, o la discreción o, por qué no, para la justificación ${ }^{52}$. Justificación en la que se exige

\footnotetext{
50. Cfr. Ibídem. Pág. 79.

51. WITTGENSTEIN, Ludwig: Tractatus lógico-philosophicus, Alianza Editorial, Madrid, 1973. (Traducción de Tierno Galván).

52. Cfr. DUSSEL, Enrique: "Historia y Praxis", en Praxis latinoamericana y Filosofía de la Liberación, Textos Completos, Edición en: http://www.scribd.com/ doc/25084350/Dussel-Enrique-Praxis-latinoamericana-y-filosofia-de-la-liberacion1983, [Consultado el 10 de mayo de 2011], Oaxtepec, 1980. Pág. 319.
}

Facultad de Derecho y Ciencias Sociales - Universidad de Valparaíso - Chile 
ideológicamente "modestia intelectual", como solicita Popper en tan famosa entrevista de 1984 en la que tilda las intenciones filosóficas como palabras grandilocuentes, en contraste de sus propias ideas e intenciones que sólo evidencian sencillez ${ }^{53}$.

¿Pero no son también sencillas las palabras y necesidades de las mayorías pobres? ¿Qué queda entonces para los oprimidos, para esas mayorías que claman silenciosamente libertad? Ya Dussel reflexionaba al respecto a comienzo de los ochenta: "Si sobre esto 'no se puede hablar (man nicht sprechen kann)', habrá antes que silenciar asesinando a millones y millones que claman: "iTengo hambre!" ${ }^{4}$.

$\mathrm{Al}$ respecto, también Adela Cortina enfatiza:

"Si lo ético cae entre ' lo que no se puede hablar, mejor es callar', es necesario que el campesino salvadoreño calle del napalm que se le arroja para impedir su liberación. Es posible que la aristocracia vienesa - a la que pertenecía el gran lógico- puede ser escéptica y hablar de pocas cosas, pero ese escepticismo se vuelve éticamente cínico cuando es necesario gritar — no sólo hablar - al sistema sobre su horrible perversidad y formular positivamente lo necesario para la liberación" 55 .

En América latina se ha venido dando en los últimos siglos un fecundo escenario para este tipo de ideologías; y en Hayek — como ha sucedido paradigmáticamente en el caso de la sociedad chilena, por ejemplo ${ }^{56}$ - o en Popper, entre otros, se han encontrado soportes para

53. POPPER, Karl: “Contra las grandes palabras”, Londres, 1984, en: http:// padron.entretemas.com/OtrasSecc/Descargas/ContraLasGrandesPalabras.pdf [Consultado el 10 de mayo de 2011]. Pág. 242.

54. Ibídem. Pág. 320.

55. CORTINA, Adela: Razón comunicativa y responsabilidad solidaria, Sígueme, Salamanca, 1985. Pág. 43.

56. Cfr.,HINKELAMMERT, Franz: El nihilismo al desnudo. Los tiempos de la globalización, op. cit.

Revista de Ciencias Sociales - Número 64 (2014) - Universidad de Valparáíso - ISSN 0716-7725-Valparaíso, Chile 
implementar sistemas ideológicos de mercado que han borrado de un plumazo toda construcción social medianamente establecida; como también se han hallado respaldos para privatizar los bienes del Estado y flexibilizar las leyes del propio mercado, y con ellas, las del trabajo. De paso, se han justificado dictaduras militares, en las que se han asesinado a cientos de miles de civiles, entre tantos otros desaparecidos, pero sobre los cuales no se ha puesto en duda el concepto de violencia. Por ello, por ejemplo, no nos extraña cuando Hinkelammert se atreve a denunciar en Popper un cierto lenguaje que, aunque se jacte de ser científico, no es más que un lenguaje de "cuarteles", pues, comenta:

"No sorprende, por tanto, que Popper suba al primer plano en aquellas sociedades en las que se impone la política de la Seguridad Nacional desde los cuarteles, y de allí que se haya transformado en el principal filósofo de las dictaduras militares de América del Sur" 57 .

\subsection{Anti-utopías liberadoras}

Desde otro lugar de la realidad, nace un tipo de antiutopismo que no quiere que prevalezca el estado factual, por eso dibuja un momento caótico, con tal de detener su posibilidad, revirtiendo el paradigma dominante que nos conduciría a su naturalización. Es asî como en Un mundo feli $z^{58}$ (1932), Aldous Huxley, por ejemplo, diseña un lugar de democracia-dictadura perfecta, donde bajo el sistema de pan y circo los esclavos amarían ser servidumbre. Donde se estima y calcula la natalidad, y por lo mismo los recién nacidos son traídos al mundo en probeta, y categorizados genéticamente para pertenecer a cinco estratos de la población, con tal de que todos puedan desarrollar al máximo sus destrezas sin mayor problematización aspiracional (a cada cual lo suyo), de esta forma, todos podrán ser felices (ayudados de todas formas por una droga de la felicidad)... y los que no, se les confina

57. HINKELAMMERT, Franz: Crítica a la razón utópica, op. cit. Pág. 222.

58. Cfr., HUXLEY, Aldous: Un mundo feliz, Plaza y Janés, Barcelona, 1969.

Facultad de Derecho y Ciencias Sociales - Universidad de Valparaíso - Chile 
a colonias especiales donde podrán igualmente ser felices entre insatisfechos.

En Huxley, se manifiesta una crítica futurística donde se puede advertir la gran utopía capitalista del sistema neoliberal que le tocó vivir, y que adelanta una utilización de la ciencia y la técnica desmedida e ingenua, con el peso de sus propios avances. Así mismo, está también el caso de George Orwell, y su libro $1984^{59}$, en el que describe una imagen similar al texto de Huxley, pero desde una crítica a la ideología marxista, la que, de igual manera que en el inglés, usa su experiencia vital en contra del totalitarismo. En la obra, la fuerza de la opresión es capaz de destruir al más fuerte, e incluso al amor. En ella se muestra el poder de la represión que es capaz de enajenar al mejor de los mortales, y convertirlo en uno más de la masa, creándole necesidades, y haciéndole querer lo que no quiere; y al fin y al cabo, apoderándose totalmente de su persona.

Si en estas obras se trataran utopías cumplidas, con verdad haríamos nuestras las palabras de Huxley:

"Las utopías parecen mucho más realizables hoy de lo que se creía antes. Y ahora nos encontramos ante otro problema igualmente angustioso: ¿̇cómo evitar su realización definitiva?... Tal vez comenzará una nueva era en la que los intelectuales y la clase cultivada soñará con el modo de vivir las utopías y con regresar a una sociedad no utópica, menos perfecta, pero más libre" 60 .

En este caso, la utopía hecha realidad, se vuelve pesadilla, pesadilla de la que se querrá despertar. Mas no es tan iluso pensar en algo así, pues las propias utopías que comienzan siendo críticas, una vez que han conseguido algún piso ideal, se vuelven conservadoras y defensoras de una realidad que ellos mismos empiezan a cerrar para sí. Estos cerrojos que se imponen, pueden producir distintos tipos de

\footnotetext{
59. Cfr., ORWELL, George: 1984, Destino, Barcelona, 2009.

60. HUXLEY, Aldous: Un mundo feliz, op. Cit. Pág. 96.
} 
cárceles, lo que al fin y al cabo, no estarían tan alejadas de aquellas pesadillas descritas en las obras antiutópicas que hemos recién comentado. De ahí que es imprescindible no alejar el concepto de utopía con el de historia. Y al no alejar, decimos y afirmamos, para toda utopía, que no existe ni existirá salto de una realidad a otra, pues la construcción de toda utopía será realizable en clave de praxis histórica, que es imposible de predecir, pues es "haciendo" en el acto, en su gerundio que "realiza realizando". De ahí que la tarea para todo proyecto utópico, deberá considerar los mecanismos que se puedan ir adaptando a las necesidades del momento, a abrirse al presente histórico determinado, aunque direccionado por este mecanismo ideal de futurización que lo irá impulsando y que nunca lo dejará estancado en un fin, en un acabamiento histórico, en la muerte o el fin de la historia.

\section{Utopías de la liberación. A modo de conclusión}

Hablar de utopía de la liberación, es hablar de utopías que puedan delatar el estado factual — que es opresivo — y conducirlo hacia su contrario. En Latinoamérica, como lugar de utopía, podemos advertir mucha bibliografía al respecto. Realizar una utopía en Nuestra América (La América de Martí), por ejemplo, sería proyectar un lugar en el que todos puedan decir ahí quepo yo; en el que aquellos deseos y formas de vida fueran encaminadas hacia el respeto y hacia la justicia; hacia el reconocimiento de las diversas culturas, necesidades, epistemologías. Que la utopía sea liberada, consiste, entonces, en que ésta pueda hacerse cargo de las verdaderas dificultades que la oprimen, y para eso, debe escribirse desde su lugar de enunciación y con las diversas personas que la conforman.

Escribir una utopía de la liberación desde insatisfacciones foráneas no haría otra cosa sino la constitución de una utopía obtusa, y como ha sido hasta ahora en Latinoamérica, de una utopía de la opresión, Por ello, entonces, deberemos realizar una última acepción al término, y es que, en adelante, cuando hablemos de utopía, de una utopía que pueda revertir la situación de los pueblos, tendremos que pensar en una utopía que se haga cargo críticamente de la realidad; que pueda distinguir entre lo natural y lo naturalizado; que pueda

Facultad de Derecho y Ciencias Sociales - Universidad de Valparaíso - Chile 
rechazar lo que se le ha impuesto como método para conseguir la felicidad de unos pocos. Tendremos que verificar, por lo tanto, que la utopía sea una utopía liberada, pues, en el acto, una utopía liberada, que es crítica y creadora, podrá constituirse en utopía de la liberación. La creación de mundos alternativos es una primera pista, la que caracteriza a la mayoría de las utopías, y sus lugares imaginados; pero no serán lugares imaginados los que necesariamente comprometan la praxis de una utopía de la liberación, pues la utopía, como parte de la historia, tiene que "necesariamente" desarrollarse desde ella y con ella, como parte de un mismo continuo ${ }^{61}$. Así pues, historia y utopía se tienen que dar relacionalmente, íntimamente, pues, como nos recuerda José Santos en su libro Conflicto de representaciones. América Latina como lugar para la filosofía, si no ocurre así, si "la historia misma no atiende a la utopía, si se presenta como plenitud o determinación, no es más que ‘historia justificación'; es reaccionaria”. Y el cambio, entonces, vendrá, si es realmente esta utopía, utopía-historia.

A este tipo de efectividad de la utopía, cuando es histórica, Fernando Aínza la llama "operatividad histórica" ${ }^{2}$, pues es capaz de transformar lo que pareciera hoy en día imposible de hacer: cambiar la realidad histórica establecida y presentada como cerrada. Desde aquí el temor que provoca, y el rechazo que hasta el día de hoy ha llevado con ellas.

El vasco salvadoreño Ignacio Ellacuría, nos reclama para la construcción de una utopía de la liberación, que llama Civilización de la Pobreza, un profetismo de denuncia, a través de un proceso de negación superador que le va trazando el camino. De esto afirma que la utopía tendrá que ser "un proyecto global universalizable", en el que "la negación del particularismo reductor lleve a la afirmación de que sólo puede ser aceptable para la humanidad nueva un proyecto que sea universalizable" ${ }^{63}$. Esta universalidad del proyecto dinámico, aclara

61. Cfr., CERUTTI Guldberg, Horacio: 500 años después. Presagio y tópica del descubrimiento, UNAM, México DF, 1991. Págs. 341-342.

62. Cfr., AÍNSA, Fernando: De la edad de oro a El Dorado, FCE, México DF, 1998. Pág. 40.

63. ELLACURÍA, Ignacio: “Utopía y profetismo”, op. cit. Pág. 409.

Revista de Ciencias Sociales - Número 64 (2014) - Universidad de Valparáíso - ISSN 0716-7725-Valparáiso, Chile 
Ellacuría, no tratará de uniformizar, y menos desde el lado de los más poderosos, sino que tratará de enriquecer a las partes, de modo que - como habíamos señalado- éstas se respeten y potencien.

En efecto, aunque este modo de posibilitación no cuente con una presencia concreta en la historia, Ellacuría dirá que basta con que muestre el modo como algo debe ocurrir para ser considerado formalmente histórico; de hecho, sin este momento determinante de la historia, no es posible hablar de historia. De esta historia ampliada que se irá enriqueciendo con cada uno de los elementos e instituciones que la conforman, podrá ir convirtiendo procesualmente la vida en una vida cada vez más humana ${ }^{64}$. Y para estos propósitos, es menester entonces realizar esa labor profética, que será la forma dialéctica con la que se irá constituyendo la utopía. Pues la profecía — dice Ellacuría- es pasado, presente y futuro, aunque sobre todo presente de cara al futuro y futuro de cara al presente. Y la utopía "es historia y metahistoria, aunque es sobre todo metahistoria, nacida, sin embargo, de la historia y remitente inexorablemente a ella, sea a modo de huida o a modo de realización. De ahí la necesidad de poner bien los pies en una tierra determinada para no perder fuerza". Es, al fin, el profetismo método, y la utopía horizonte.

Desde aquí, es preciso afirmar que la realidad del presente que comienza en un "no" (que de esto no hay nada más que nada), huye de sí hacia —en palabras de Bloch— "el ser del todo” y no hacia "másnada". Teniendo esas dos posibilidades, cual fracaso o éxito, la esperanza anima la conquista del ser, afirmando el carácter procesual, abierto y posible de aquella realidad histórica justa y en libertad que está por venir, que es lograda desde su posibilidad. En este sentido, el presente de los pueblos latinoamericanos, y de las personas y las comunidades olvidadas, en general, está referido a un futuro "aún- no- acontecido", pero que, en el fondo, es una opción a favor de su futuro, y a favor de la historia; de su pervivencia y no de su fin; y con ello, una apuesta por las personas y las comunidades; por la conquista de la vida que brota desde abajo.

64. Cfr. Ibídem. Págs. 419-450

Facultad de Derecho y Ciencias Sociales - Universidad de Valparaíso - Chile 
Así, pues, si bien podríamos decir que algo tiene de la República de Platón como añoranza de una tierra ejemplar, justa y comunitaria, sin guerras y sin pobrezas, y donde el filósofo se compromete en ella; o también de la maravillosa isla Utopía de Tomás Moro, en la que es fundamental igualmente la vida buena y comunitaria; y de la Ciudad del Sol de Campanella, liberada de todo mal; o de la Nueva Atlántida de Bacon, en la que reina el ser humano, en un estado ideal diseñado por la ciencia; en la utopía de Ellacuría, se revela, también, la realización de un mundo nuevo, pero ahora en el mismo mundo que tenemos; revirtiendo su historia, subvirtiéndola y lanzándola en otra dirección ${ }^{65}$.

\section{BIBLIOGRAFÍA}

AÍNSA, Fernando: De la edad de Oro a El Dorado, FCE, México DF, 1998.

AÍNSA, Fernando: La reconstrucción de la utopía, Ediciones del Sol, Buenos Aires, 1999.

BERGER, Peter: El Dosel sagrado: Elementos para una sociología de la religión. Amorrortu editores, Buenos Aires, 1971.

BERGER, Peter: Una gloria lejana, Herder, Barcelona, 1994.

BLANCO, Rogelio: La ciudad ausente. Utopía y Utopismo en el pensamiento occidental, Ediciones Akal, Madrid, 1990.

BLOCH, Ernst: El principio esperanza, Aguilar, Madrid, 1977.

CAMPANELLA, Tomaso: La ciudad del sol, Fondo de Cultura Económica, México, 1980.

CERUTTI GULDBERG, Horacio: De varia utópica (Ensayos de Utopía III), Publicaciones de la Universidad Central de Bogotá,

Colombia, 1989.

CERUTTI GULDBERG, Horacio: 500 años después. Presagio y tópica del descubrimiento, UNAM, México DF, 1991.

CORTINA, Adela: Crítica y utopía: La escuela de Frankfurt, Cincel, Madrid, 1985.

65. ELLACURÍA, Ignacio: “El desafío de las mayorías pobres”, op. cit. Pág. 1078.

Revista de Ciencias Sociales - Número 64 (2014) - Universidad de Valparáíso - ISSN 0716-7725-Valparaíso, Chile 
CORTINA, Adela: Razón comunicativa y responsabilidad solidaria, Sígueme, Salamanca, 1985.

DUSSEL, Enrique: "Historia y Praxis", en Praxis latinoamericana y Filosofía de la Liberación, Textos Completos, Edición en: http:// www.scribd.com/doc/25084350/Dussel-Enrique-Praxislatinoamericana-y-filosofia-de-la-liberacion-1983, [Consultado en mayo de 2014], Oaxtepec, 1980.

ELLACURÍA, Ignacio: “El desafío de las mayorías populares”, Revista de Estudios Centroamericanos (ECA), $\mathrm{n}^{\circ}$ 493-494, UCA editores, San Salvador, 1989, pp. 1077-1078.

ELLACURÍA, Ignacio: "Utopía y profetismo desde América Latina; un ensayo concreto de soteriología histórica", Revista Latinoamericana de Teología, ${ }^{\circ}$ 17, UCA EDITORES, 1989, PP. 141184. REIMPRESO EN ELLACURÍA, I. - SOBRINO, J., (COMPS.) Mysterium Liberationis, Tomo 1, Editorial Trotta - Fundación Xavier Zubiri, Madrid, 1990, pp. 393-442.

FERRATER MORA, José: Diccionario de Filosofía, Editorial Sudamericana, Buenos Aires, 1965.

FORNET-Betancourt, Raúl: Tareas y Propuestas de la filosofía Intercultural, de Concordia, serie Monografías, tomo 49, Aachen, 2009.

HABERMAS, Jürgen: "El fin de una utopía”, El País, 9 de diciembre de 1984, pp. 14-15. Discurso pronunciado en Madrid, en el Congreso de los Diputados, el 26 de noviembre de 1984.

HAYEK, Friedrich: "La Pretensión del Conocimiento", en d́Inflacióno pleno empleo?, Unión Editorial, Madrid, 1976, y HAYEK,

Friedrich: "Entrevista en el Mercurio", diario El Mercurio, 12 de Abril de 1981, Santiago de Chile, pp. D8-D9.

HEGEL, Friedrich: Filosofía del derecho, Editorial Claridad, Buenos Aires, 1968.

HINKELAMMERT, Franz: Crítica a la razón utópica, Editorial DEI, San José, Costa Rica, 1990.

HINKELAMMERT, Franz: El nihilismo al desnudo. Los tiempos de la globalización, LOM ediciones, Santiago de Chile, 2001.

HOPENHAYN, Martín: "Utopías del Renacimiento, Moro, Campanella y Bacon”, en Estudios Públicos, $\mathrm{N}^{\circ} 39$, Santiago de Chile, 1990.

Facultad de Derecho y Ciencias Sociales - Universidad de Valparaíso - Chile 
Sobre Utopías, antitutopías y liberación. Aproximaciones y precisiones desde...

HUXLEY, Aldous: Un mundo feliz, Plaza y Janés, Barcelona, 1969. www.rae.es/Utopía. [Consultado en mayo de 2014].

MANNHEIM, Karl: Ideología y utopía. Una introducción a la sociología del conocimiento, Fondo de Cultura Económica, México, 1987.

MORHE, Thomas: Utopía, Ediciones Akal, Madrid, 1997.

NEUSÜSS, Arnhelm: Utopía, Barral Editores, Barcelona, 1971.

ORWELL, George: 1984, Destino, Barcelona, 2009.

POPPER, Karl: “Contra las grandes palabras”, Londres, 1984, en: http:/ /padron.entretemas.com/Otras Secc/Descargas/

ContraLasGrandesPalabras.pdf [Consultado en mayo de 2014].

POPPER, Karl: La miseria del historicismo, Editorial Alianza, 1973.

POPPER, Karl: La sociedad abierta y sus enemigos, Paidós, Buenos Aires, 1967.

POPPER, Karl: “Utopía y violencia”, en Neusüss, Arnhelm, Utopía, Barral Editores, Barcelona, 1971.

RAMOS CENTENO, Vicente: Bloch, (1885-1977), Ediciones del Orto, Madrid, 1999.

ROJAS MIX, Miguel: Los cien nombres de América: eso que descubrió Colón, Editorial de la Universidad de Costa Rica, Costa Rica, 1997.

SANTOS, José: Conflicto de Representaciones. América Latina como lugar para la filosofía, FCE, Santiago de Chile, 2010.

WITTGENSTEIN, Ludwig: Tractatus lógico-philosophicus, Alianza Editorial, Madrid, 1973. (Traducción de Tierno Galván). 